\title{
Estimation of the residual stress on the thread root generated by thread rolling process
}

\author{
Akihiro FURUKAWA* and Masaya HAGIWARA** \\ *Aoyama Seisakusho Co.,Ltd. \\ 1-8 Takahashi, Ohguchi-cho, Niwa-gun, Aichi-Pref., 480-0198, Japan \\ E-mail: akihiro@asj-fasteners.co.jp \\ **Nagoya Institute of Technology (Tsukuri College) \\ Gokiso-cho, Showa-ku, Nagoya, Aichi-Pref., 466-8555, Japan
}

Received 23 June 2014

\begin{abstract}
Yoshimoto had been presented a hypothesis concerning the fatigue strength of a bolt in bolt/nut assembly using Ishibashi's hypothesis on the relationship between the fatigue notch factor and the local stress distribution on the first thread root of a bolt mated with nut. By using Yoshimoto's hypothesis, the effect of the manufacturing process (sequence or order of thread rolling and heat treatment processes) on the fatigue strength can be explained in connection with the axial residual stress at the first thread root of a bolt as a change of mean stress level. However, this hypothesis has not yet been verified quantitatively since the axial residual stress which may exist locally around the thread root could neither be measured nor estimated with sufficient accuracy. This study aims to quantify the axial residual stress on the thread root generated by thread rolling process. For this purpose, a method for simulating thread rolling process by using 3D elastic-plastic FEM was proposed to estimate the axial residual stress distribution by using precisely determined material property. Calculated results for two types of test specimens, one is grooved specimen with larger root radius and the other is leadless bolt specimen having the same thread profile as M10 $\times 1.25$ bolts, show that the axial compressive residual stress of $1000 \mathrm{MPa}$ level is generated at the root of the specimens. Finally, the validity of the simulation was confirmed through the X-ray stress measurement for grooved specimen, and the fatigue tests for leadless bolt specimen.
\end{abstract}

Key words : Fixing element, Bolt, Fatigue strength, Yoshimoto's hypothesis, Residual stress, Thread root, Thread rolling, 3D FE analysis

\section{Introduction}

Many investigations have been performed to predict the fatigue strength of a bolt to ensure the safety of bolted joints. The compressive axial residual stress on the thread root of a bolt, which is generated by thread rolling process and thought to be diminished or disappeared by heat treatment (quenching and tempering), is one of the primary factors influencing significantly on the fatigue strength of a bolt in bolt/nut assembly. Yoshimoto (Yoshimoto, 1983) had presented a hypothesis to explain the difference of the fatigue strength between the bolts thread rolled before heat-treated (called SV bolt) and those thread rolled after heat-treated (called SG bolt) based on the Ishibashi's hypothesis (Ishibashi, 1969) concerning the effect of the stress concentration on the fatigue strength.

Afterward, Hagiwara et al. (Hagiwara et al., 1990) modified Yoshimoto's hypothesis taking into account the yield property of the bolt material. However, the hypothesis has not yet been verified quantitatively. One of the major reasons is the difficulty to quantify the residual stress locally acting on the thread root. Hagiwara et al. (Hagiwara et al., 1989) tried to measure the residual stress on the bolt thread root by using X-ray diffraction method and Heyn-Bauer method, and Kim et al. (Kim et al., 2007) has tried to quantify the residual stress at the groove-rolled product by direct measurement and estimation using 3D FE analysis. However, we are still not able to answer the simple question how much the residual stress is generated on the bolt thread root by thread rolling process. The results from the studies 
formerly performed only show that the residual stress of SG bolts may vary from a few hundred MPa to more than thousand MPa.

This study aims to enable the precise estimation for the axial residual stress distribution on the thread root generated by thread rolling process. For this purpose, a method is proposed for simulating thread rolling process by using 3D FEM. The method is applied to the grooved specimen having larger root radius and threaded specimen without lead (called leadless bolt hereafter) to verify the validity of the results estimated by comparing them to the result from X-ray measurement and that from fatigue tests conducted, respectively.

\section{Nomenclature}

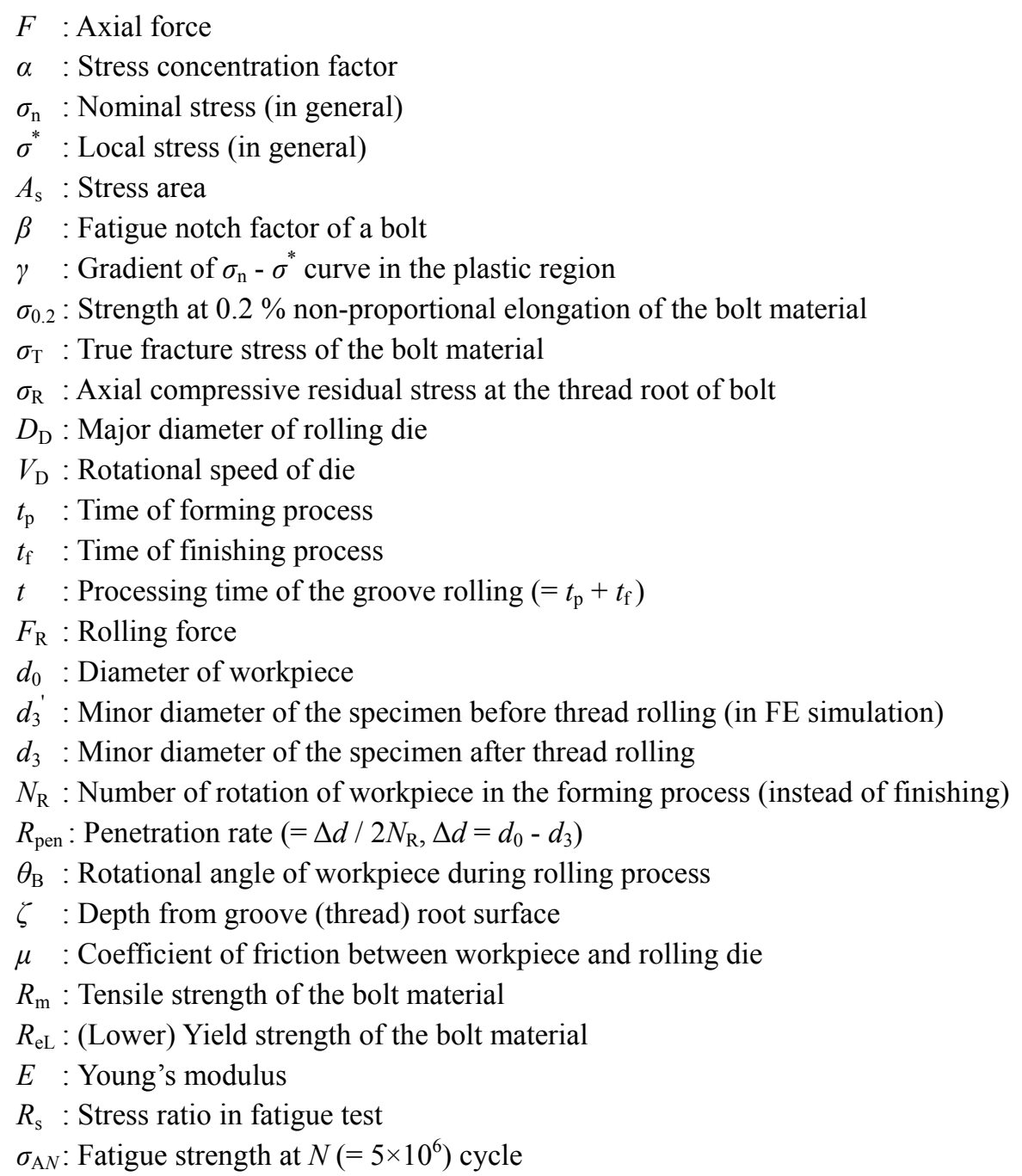

\section{Hypotheses on the fatigue strength of a bolt in bolt/nut assembly}

Figure 1 shows the local stress distribution around the first thread root of a bolt in bolt/nut assembly.

When the axial force $F\left(=\sigma_{\mathrm{n}} \cdot A_{\mathrm{s}}\right)$ is applied to the bolt/nut assembly, the maximum stress $\alpha \cdot \sigma_{\mathrm{n}}$ is generated on the surface of the first thread root mated with nut. According to Ishibashi's hypothesis, the stress which influences on the fatigue strength is the local stress $\sigma^{*}$ at the $\varepsilon_{0}$ inner layer from the thread root surface. This means that the fatigue notch factor $\beta$ can be defined as the magnitude of the stress $\sigma^{*}\left(=\beta \cdot \sigma_{\mathrm{n}}\right)$. The depth $\varepsilon_{0}$ is thought to be dependent upon the crystal grain size. It might be the order of several dozen $\mu \mathrm{m}$.

Figure 2 shows the assumed relationship between the local stress $\sigma^{*}$ and the nominal stress $\sigma_{\mathrm{n}}$. The red line represents the case with SV bolts in which no axial residual stress exists. In the Yoshimoto's hypothesis, the material property of the bolt had originally been assumed to be the elastic-perfectly-plastic body $(\gamma=0)$ and it modified by Hagiwara et al. (Hagiwara et al., 1990) to be the elastic-plastic body $(0<\gamma<\beta)$ afterward. In the case where the 


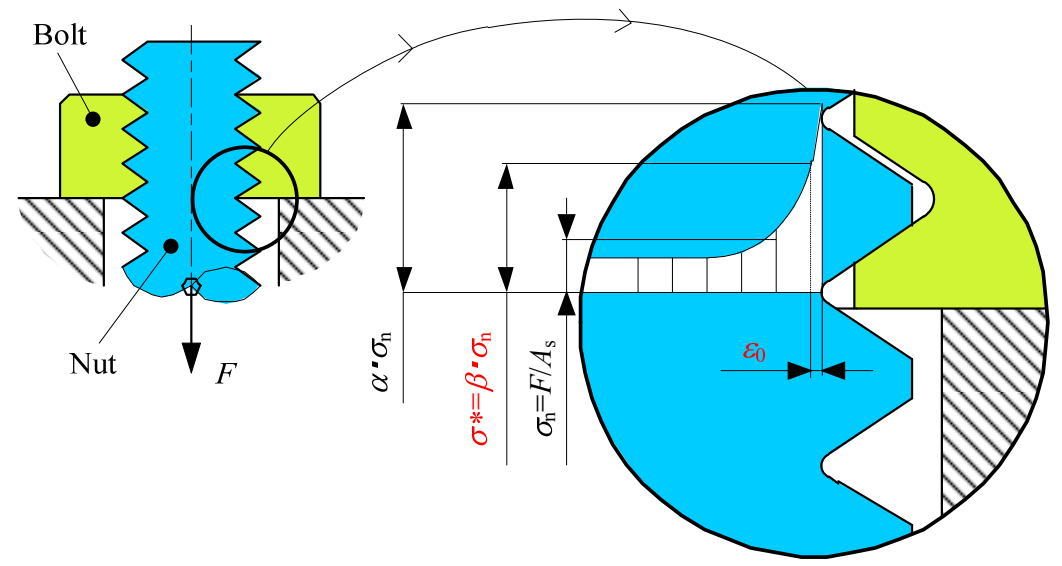

Fig.1 Local stress distribution on the first thread root of a bolt in bolt/nut assembly

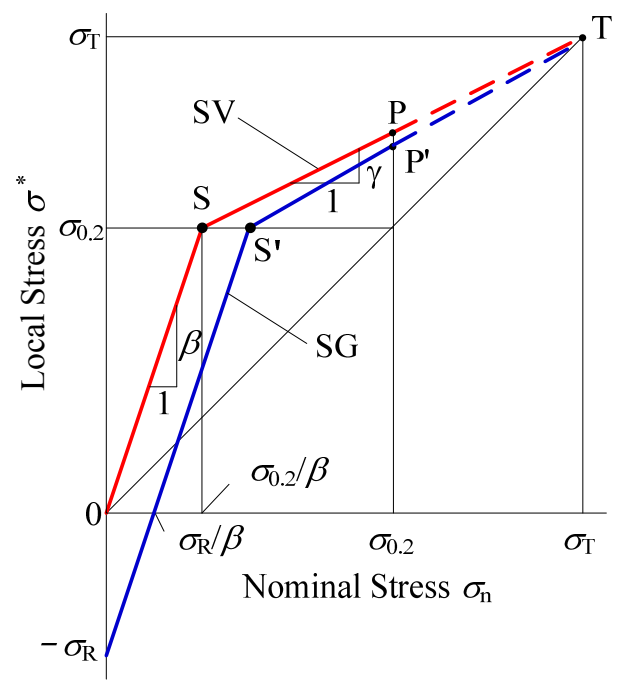

Fig. 2 Assumed relationship between local stress and nominal stress on the thread root of a bolt at $\varepsilon_{0}$ inner layer (Hagiwara et al., 1990)

axial compressive residual stress $\sigma_{\mathrm{R}}$ exists on the thread root as in the case with SG bolt, it works to decrease the axial stress, and the relationship is shifted from the red line to the blue one.

By using these relationships shown in Fig. 2, the fatigue limit diagrams (Haigh diagrams) for SV and SG bolts can be drawn as shown in Fig. 3. In this figure, all the stresses are expressed by nominal stress, and therefore the fatigue strength of the SV bolt seems to be decreased by $\beta$ against the fatigue strength of the notch free specimen on the ordinate. This figure highlights that the fatigue strength of a bolt with axial compressive residual stress seems to be increased especially in the region where the mean stress is relatively low. According to Yoshimoto's hypothesis, the difference of the fatigue strength between the SV bolt and the SG bolt can be quantified by the magnitude of the axial compressive residual stress $\sigma_{\mathrm{R}}$ at the thread root divided by the fatigue notch factor $\beta$.

\section{A method proposed for simulating thread rolling process by 3D FEM 4.1 Procedure}

In this study, the general-purpose FEM software ANSYS ${ }^{\circledR}$ is used for the simulation of thread rolling process to estimate the axial residual stress distribution precisely. The reason comes mainly from the fact that the axial residual stress distribution estimated by FE simulation will be used as the initial condition for the stress analysis to follow, in which the local stress condition at the first thread root of a bolt in bolt/nut assembly is determined in the fatigue loading. By the other FEM softwares commercially available to simulate plastic forming processes, the stress concentration locally induced in very small region cannot be evaluated with sufficient accuracy. 


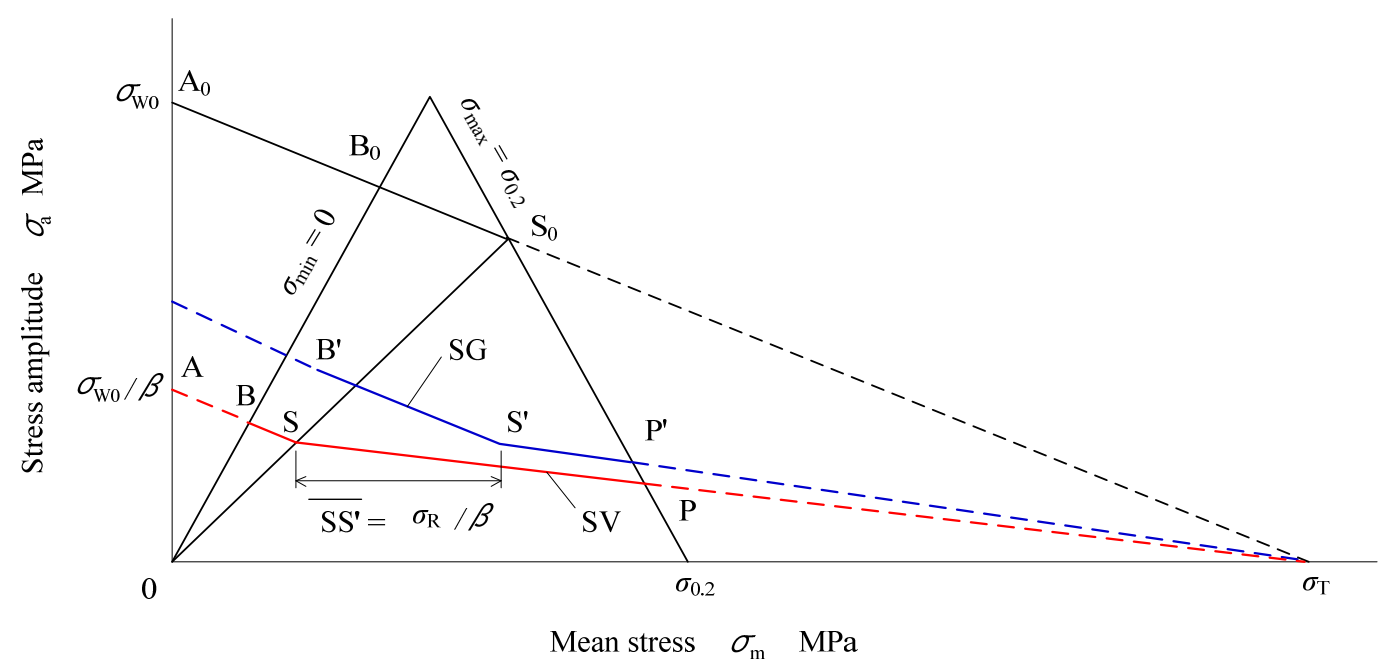

Fig.3 Fatigue limit (Haigh) diagram of a bolt derived from Fig. 2 using modified Yoshimoto's hypothesis (Hagiwara et al., 1990)

On the other hand, ANSYS ${ }^{\circledR}$ is not equipped the auto re-meshing function through the 3D structural analysis.

Therefore, the workpiece with semi-deformed shape during the thread rolling process is modeled and meshed to obtain the final residual stress distribution. The simulation of thread rolling process consists of the following steps:

Step 1: Assume the shape of the workpiece just before final rolling process

Step 2: Load the rolling force onto the workpiece (elastic-plastic body) by the penetration of dies having rigid body. The penetration depth per rotation of workpiece is calculated using the conditions of practical (experimental) rolling process.

Step 3: Rotate the rolling dies, by which the workpiece also rotates due to the frictional force generated by the rolling force.

Step 4: Repeat Step 2 and Step 3 until the rolling force has reached the measured one.

Step 5: Release the rolling dies to unload the rolling force.

\subsection{Application to axi-symmetric test specimens}

Figures 4 and 5 show the geometry of test specimens and the rolling dies for them. The grooved specimen shown in Fig. 4 was designed so that the axial residual stress distribution on the root can be measured by X-ray diffraction method. The specimen has axi-symmetric multiple grooves as screw threads made from the blank quenched and tempered for $\mathrm{M} 10 \times 1.25$, property class $12.9 \mathrm{SG}$ bolts. The root radius of the groove is large enough so that the value of $\sin ^{2} \Psi$ ( $\Psi$ : the angle between the normal axis of specimen plane and that of diffraction plane.) can be varied from 0 to 0.6 to ensure the accuracy of measurement. The X-ray stress measurement for this grooved specimen has already been performed by the authors (Furukawa \& Hagiwara, 2009).

On the other hand, the leadless bolt specimen shown in Fig. 5 was designed to estimate the axial residual stress on the thread root of a bolt precisely, which has the same thread profile as M10 $\times 1.25$ bolts, and intended to use for the fatigue test described in clause $\mathbf{5}$. The blank is for M10 $\times 1.25$, property class $8.8 \mathrm{SG}$ bolts, and quenched and tempered before rolling.

The hydraulic thread-rolling machine with cylindrical dies (BAD DÜBEN, 2-NTR 16 CNC/AC) is used for the rolling of both the grooved specimen and the leadless bolt specimen to control the penetration rate accurately. The conditions of rolling process are summarized in Table1.

Figures 6 and 7 show the FE models and the material properties of the workpieces to be simulated, respectively. The true stress-true strain curves for the elastic-plastic material properties are determined from the results of tensile test for the machined test pieces reversely so that each tensile property can be simulated through the tensile strength by FEM with sufficient accuracy (Okubayashi et al., 2006). The portion of the rolling die which contacts to the workpiece is modeled as rigid surface, and the coefficient of friction between lubricated surfaces of workpiece and rolling dies are 


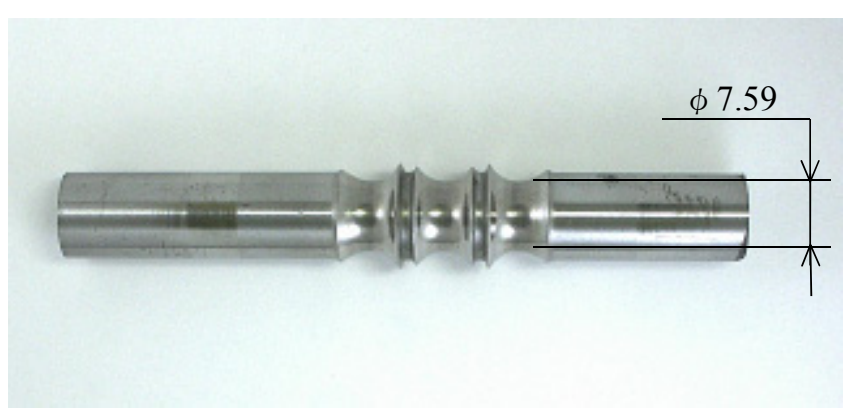

(a) Geometry

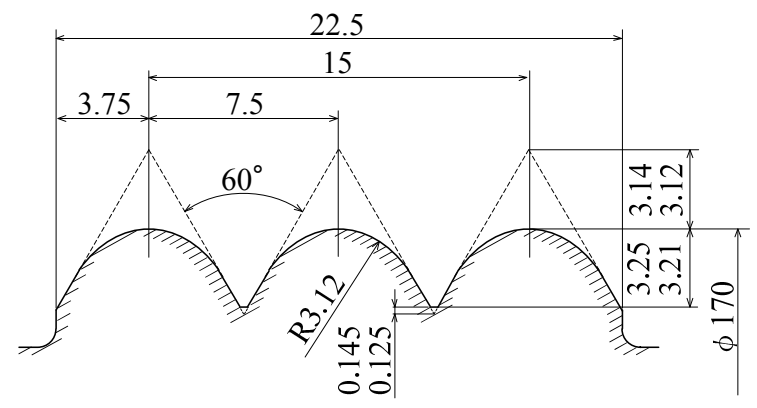

(b) Profile of the rolling die

Fig.4 Specifications of the grooved specimen

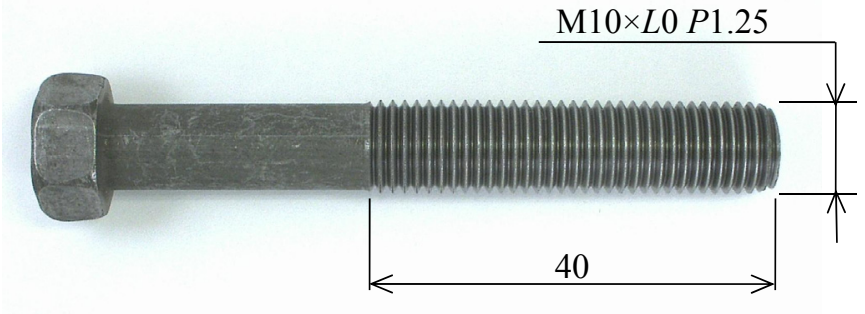

(a) Geometry

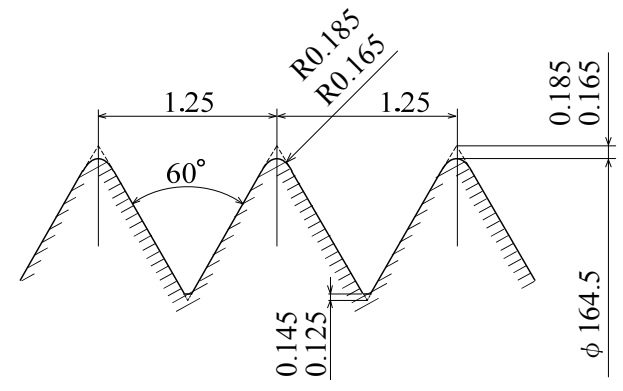

(b) Profile of the rolling die

Fig. 5 Specifications of the leadless bolt specimen

Table1 The conditions of the practical rolling process

\begin{tabular}{l|c|c}
\hline & Grooved specimen & Leadless bolt specimen \\
\hline Major diameter of rolling die $D_{\mathrm{D}} \mathrm{mm}$ & 170 & 164.5 \\
\hline Rotational speed of die $V_{\mathrm{D}} \mathrm{min}^{-1}$ & 7 & 60 \\
\hline Processing time $t \mathrm{~s}$ & 8 & 1 \\
\hline Time of forming process $\left.t_{\mathrm{p}} \mathrm{s}\right)$ & $(7.6)$ & $(0.5)$ \\
\hline (Time of finishing process $\left.t_{\mathrm{f}} \mathrm{s}\right)$ & $(0.4)$ & $(0.5)$ \\
\hline Diameter of workpiece $d_{0} \mathrm{~mm}$ & 9.02 & 9.07 \\
\hline Minor diameter after rolling $d_{3} \mathrm{~mm}$ & 7.59 & 8.34 \\
\hline Number of rotation for workpiece $N_{\mathrm{R}}$ & 17 & 9 \\
\hline Penetration rate $R_{\mathrm{pen}} \mathrm{mm} / \mathrm{rev}$. & 0.04 & 0.04 \\
\hline Maximum rolling force $F_{\mathrm{R}} \mathrm{kN}$ & 52 & 50 \\
\hline
\end{tabular}

fixed to $\mu=0.125$ in this study. The FE model for the leadless bolt is extracted to 3 crests of rolling die from the 32 crests, and the intermediate thread root rolled is evaluated as with grooved specimen to save the number of elements. By this model, the same stress distribution is expected as the leadless bolt having multiple threads and roots as long as the die having rigid body is assumed. The minor diameters of workpiece $d_{3}$ ' are determined considering the spring back after the rolling process. The conditions for FE simulation are summarized in Table2.

\subsection{Results and discussions}

\subsubsection{For grooved specimen}

Figure 8 shows the relationship between the rolling force $F_{\mathrm{R}}$ and the rotation angle $\theta_{\mathrm{B}}$ of the workpiece for the grooved specimen. The dashed line shows the measured maximum rolling force $F_{\mathrm{R} \text { max }}$ during the rolling process. In 


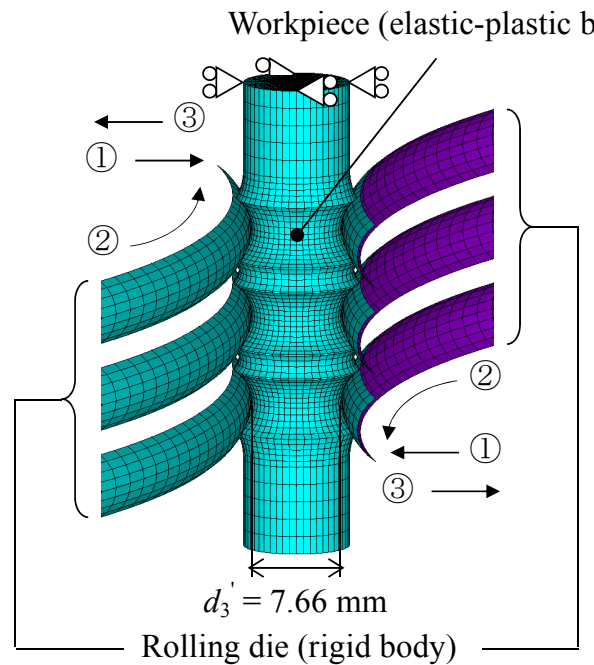

(a) FE model

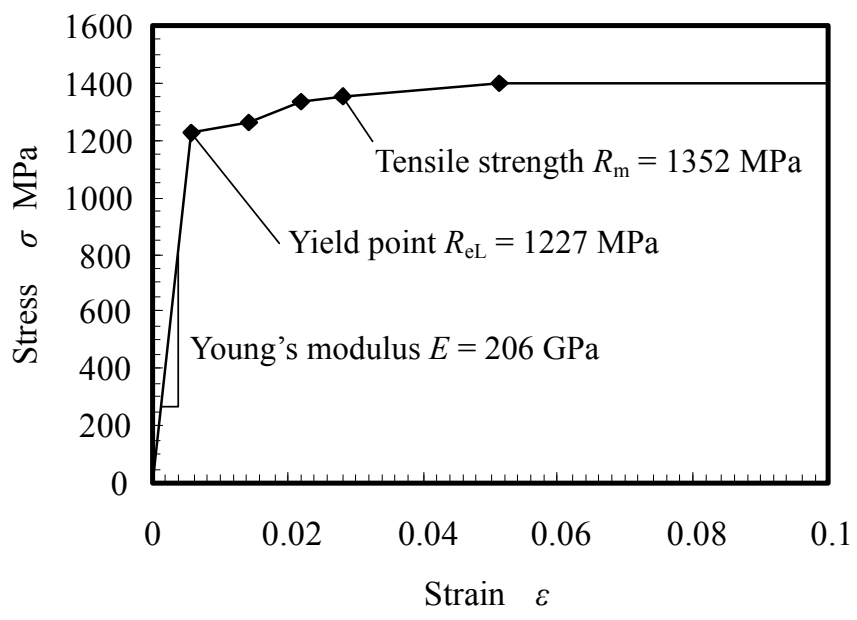

(b) Material property of the workpiece

Fig.6 FE model and material property for the FE simulation for the grooved specimen

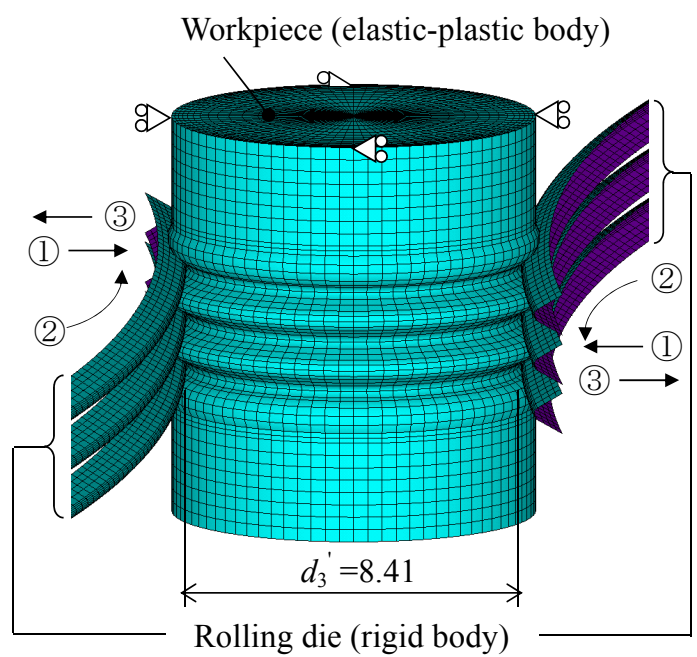

(a) FE model

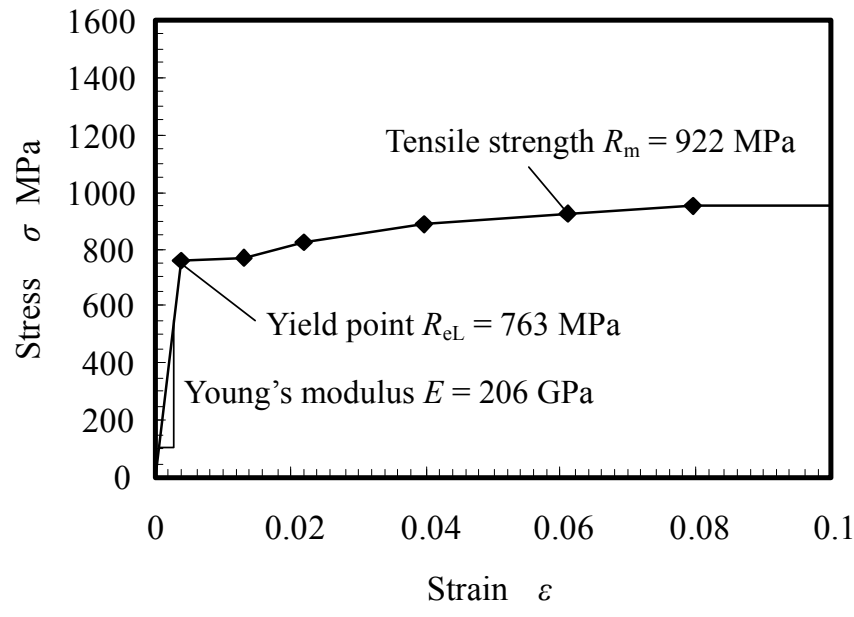

(b) Material property of the workpiece

Fig.7 FE model and material property for the FE simulation for the leadless bolt specimen

Table2 Conditions of FE simulation

\begin{tabular}{c|c|c}
\hline & Grooved specimen & Leadless bolt specimen \\
\hline Minor diameter of workpiece $^{* 1} d_{3}^{\prime} \mathrm{mm}$ & 7.66 & 8.41 \\
\hline Coefficient of friction $^{*}$ & 0.125 & 0.125 \\
\hline Penetration depth per rotation $^{* 2} \mathrm{~mm}$ & 0.04 & 0.04 \\
\hline
\end{tabular}

${ }^{*}$ : The spring back $0.01 \mathrm{~mm}$ after groove rolling is taken into account the workpiece.

${ }^{*}$ : Penetration depth per rotation of each sides of rolling die. (Total depth is $0.08 \mathrm{~mm}$ )

this case, the rolling force $F_{\mathrm{R}}$ has reached to the maximum rolling force generated during the practical rolling process in the second penetration (step 2 in clause 4.1), and decreases within a half turn to be constant level in the following rotation process (step 3 in clause 4.1). The maximum calculated rolling force shows good agreement with the measured one. The minor diameter $d_{3}=7.57 \mathrm{~mm}$ obtained in the simulation is almost the same as the practical specimen rolled 


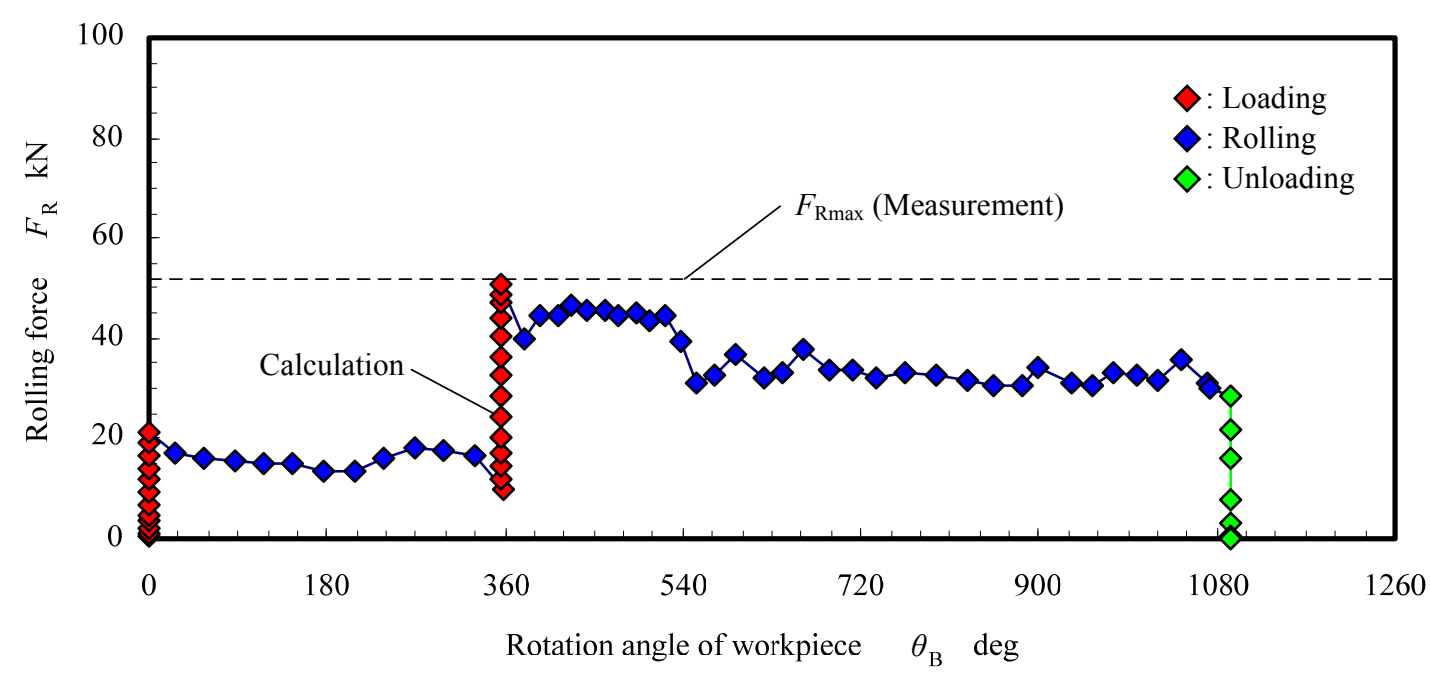

Fig.8 Relationship between the rolling force and the rotation angle of workpiece

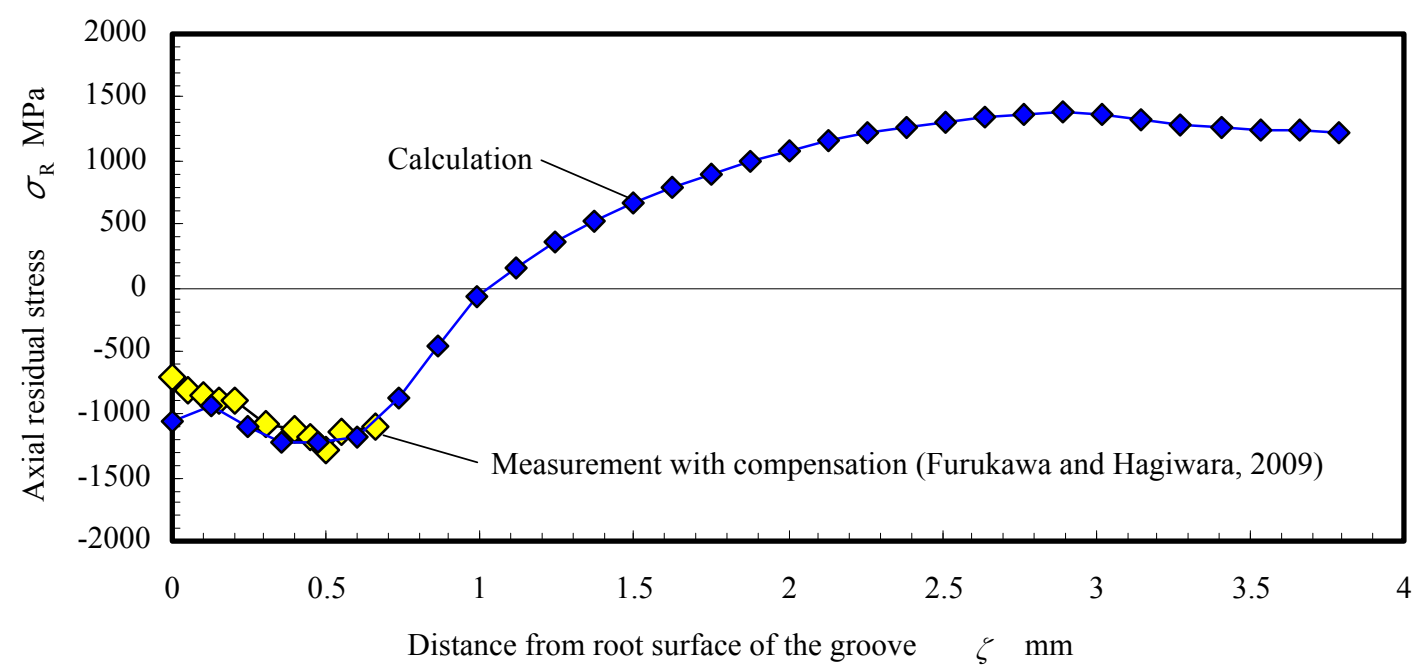

Fig.9 Comparison of the radial distributions of axial residual stress on the groove root between calculation and measurement with compensation (Furukawa and Hagiwara, 2009)

$\left(d_{3}=7.59 \mathrm{~mm}\right)$.

Figure 9 shows the comparison of the radial distribution of the axial residual stress between simulation and measurement by X-ray diffraction method with compensation (Furukawa and Hagiwara, 2009). This result shows that the calculated values show very good agreement with the measured ones.

This is an extremely important result indicating the validity and the accuracy of the FE simulation proposed.

\subsubsection{For leadless bolt specimen}

Figure 10 shows the relationship between the rolling force $F_{\mathrm{R}}$ and the rotation angle $\theta_{\mathrm{B}}$ of the workpiece for the leadless bolt specimen. This result shows that the rolling force has reached to the maximum rolling force generated during the practical rolling process in the first penetration, and it decreases within a half turn to be constant level as in the case of the grooved specimen. The maximum calculated rolling force shows good agreement with the measured one as in the case of grooved specimen and the minor diameter $d_{3}=8.35 \mathrm{~mm}$ obtained in the simulation is almost the same as the measured one $\left(d_{3}=8.34 \mathrm{~mm}\right)$ as well.

Figure 11 shows the radial distribution of the axial residual stress at the thread root estimated by FE simulation. This is the first time that the figure for the axial residual stress distribution can be shown. As mentioned in 4.3.1, the validity of the calculated axial residual stress distribution at the thread root of a bolt was guaranteed from Fig. 9 indirectly. This result shows that the maximum compressive axial residual stress $1460 \mathrm{MPa}$ exists at the $0.1 \mathrm{~mm}$ inner 


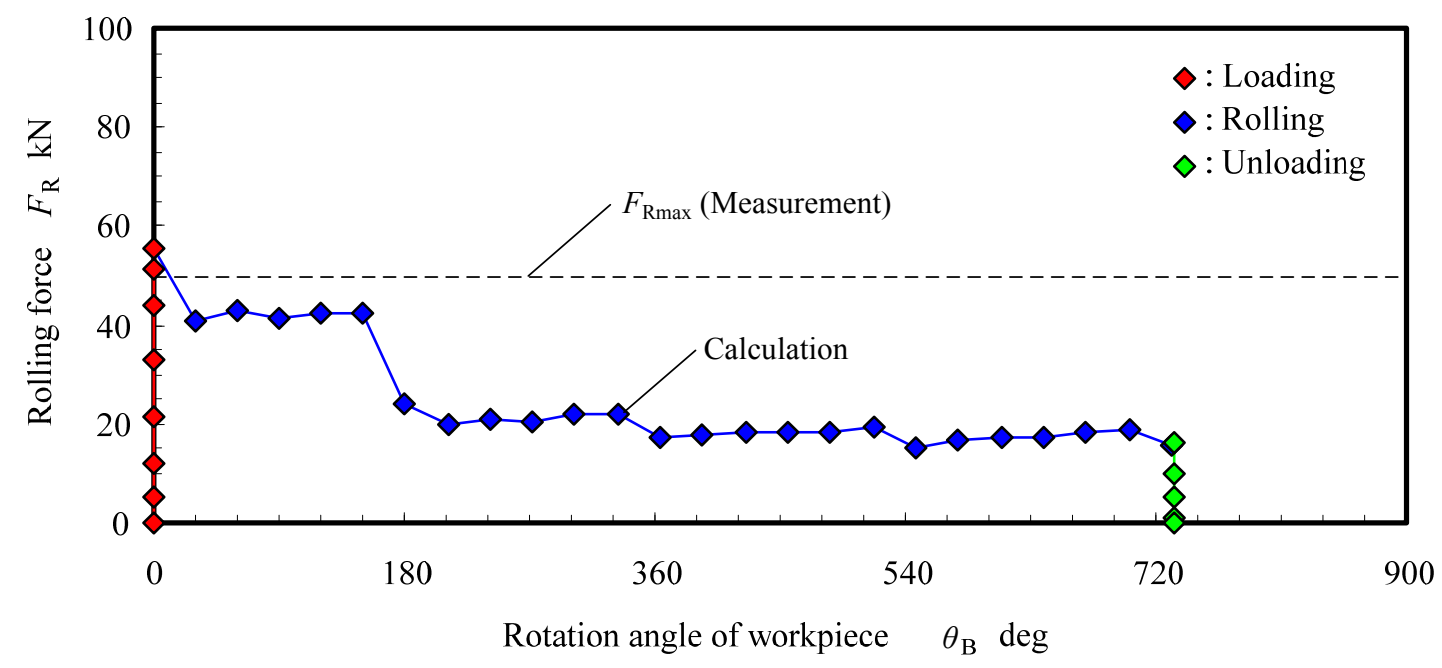

Fig.10 Relationship between the rolling force and the rotation angle of workpiece

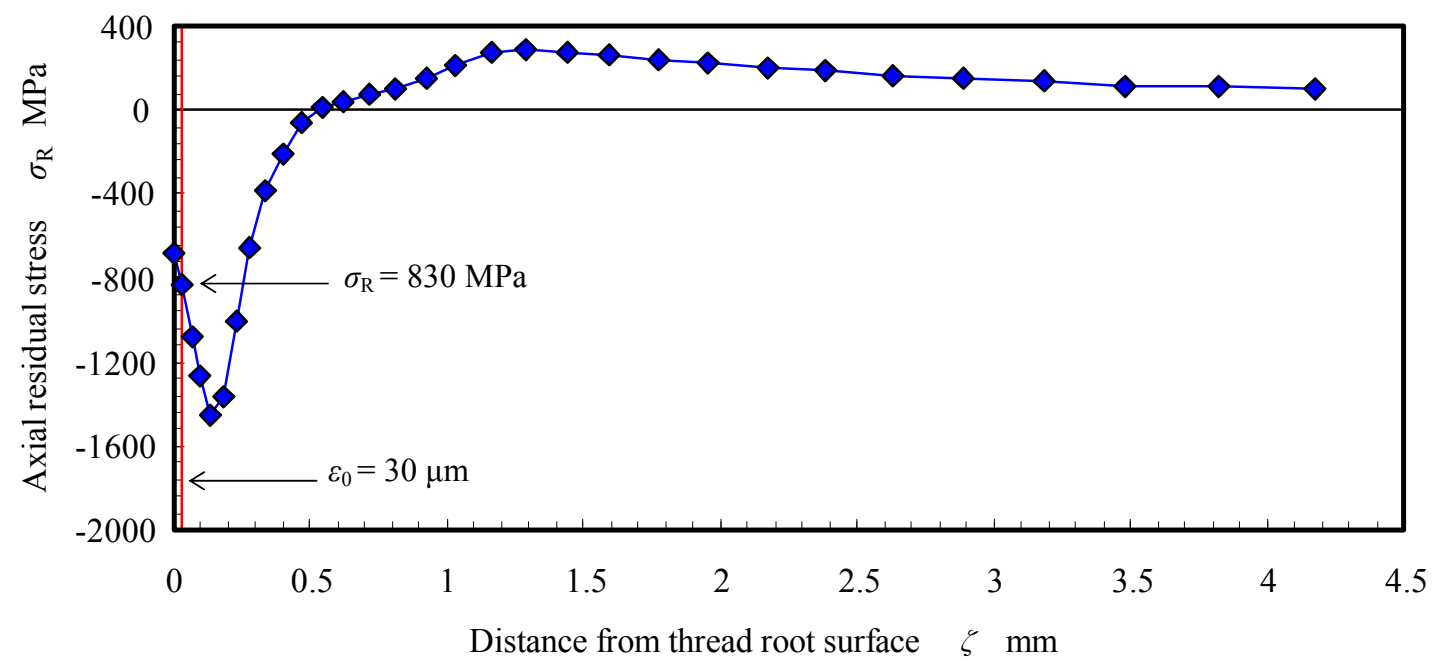

Fig.11 Radial distribution of the axial residual stress estimated by FE simulation (Leadless bolt)

layer from the thread root surface.

Mitsubayashi et al. (Mitsubayashi et al., 1995) reported that the grain diameter of the shot-peening process affects the shape of the residual stress distribution. Considering this, the difference of the shape of the axial residual stress distribution and the maximum value between the grooved specimen and the leadless bolt specimen estimated by proposed method can be explained by the difference of the crest radii of the rolling dies (see Figs. 4 and 5) and the penetration depth (see Table 1). Assuming the depth $\varepsilon_{0}=30 \mu \mathrm{m}$ as in the previous study (Furukawa et al., 2012), the compressive axial residual stress on the thread root of the leadless SG bolt specimen which influences on the fatigue strength can be estimated as $830 \mathrm{MPa}$.

\section{Verification of the simulation through the fatigue test 5.1 Testing conditions}

It was confirmed from the experiment for the groove-rolled specimens (Furukawa and Hagiwara, 2009) that the axial residual stress generated by thread rolling process disappears perfectly by heat treatment (quenching and tempering). Therefore, we can evaluate the effect of the residual stress on the fatigue strength by the fatigue tests for SV and SG leadless bolts manufactured from the same material and the same heat treatment procedure as the groove-rolled specimen.

Figure 12 shows the test conditions. The fatigue tests were performed in accordance with the staircase method with 
small samples specified in ISO3800 (ISO3800, 1993) for leadless bolts and split-type nut adapter assemblies in the loading condition of low mean stress $\left(R_{\mathrm{s}}=0.1\right)$ where the effect of the axial residual stress is thought to be significant (see Fig. 3). The main reason why we use leadless bolt (and split-type nut adapter assembly) instead of bolt/nut assembly is to exclude the unknown effect of the incomplete thread of nut (bearing surface side) upon the dynamic stress on the first thread root of a bolt, and to introduce the axial compressive residual stress as estimated in 4.3.2. The split-type nut adapter is fastened by four M2 bolts to avoid or minimize the separation between split parts due to the slippage (sliding action) at the mating thread surfaces during the test.

\subsection{Test results and considerations}

Figure 13 shows the results from staircase fatigue tests. The fatigue fracture in all failed specimens occurred at the first thread root of the leadless bolt. The result shows that the fatigue strength $\sigma_{\mathrm{A} N}\left(N=5 \times 10^{6}\right)$ of the SG leadless bolt is $44 \%$ higher than that of SV leadless bolt.

Figure 14 shows the fatigue limit diagram drawn by using nominal stress as in Fig. 3. In this figure, the fatigue strength of notch-free specimen was obtained from the estimated fluctuating fatigue strength $\sigma_{\mathrm{W} 0}$ from JSME handbook (JSME, 1982) and the true fracture stress $\sigma_{\mathrm{T}}$ measured using the method proposed by Nishihara and Sakurai (Nishihara and Sakurai, 1939). The fatigue notch factor $\beta=3.6$ was estimated reversely from the experimental result of SV leadless bolt (plot marked $\bigcirc$ ) assuming that the data are in accordance with Yoshimoto's hypothesis in the case without residual stress shown as red line in Fig. 3.
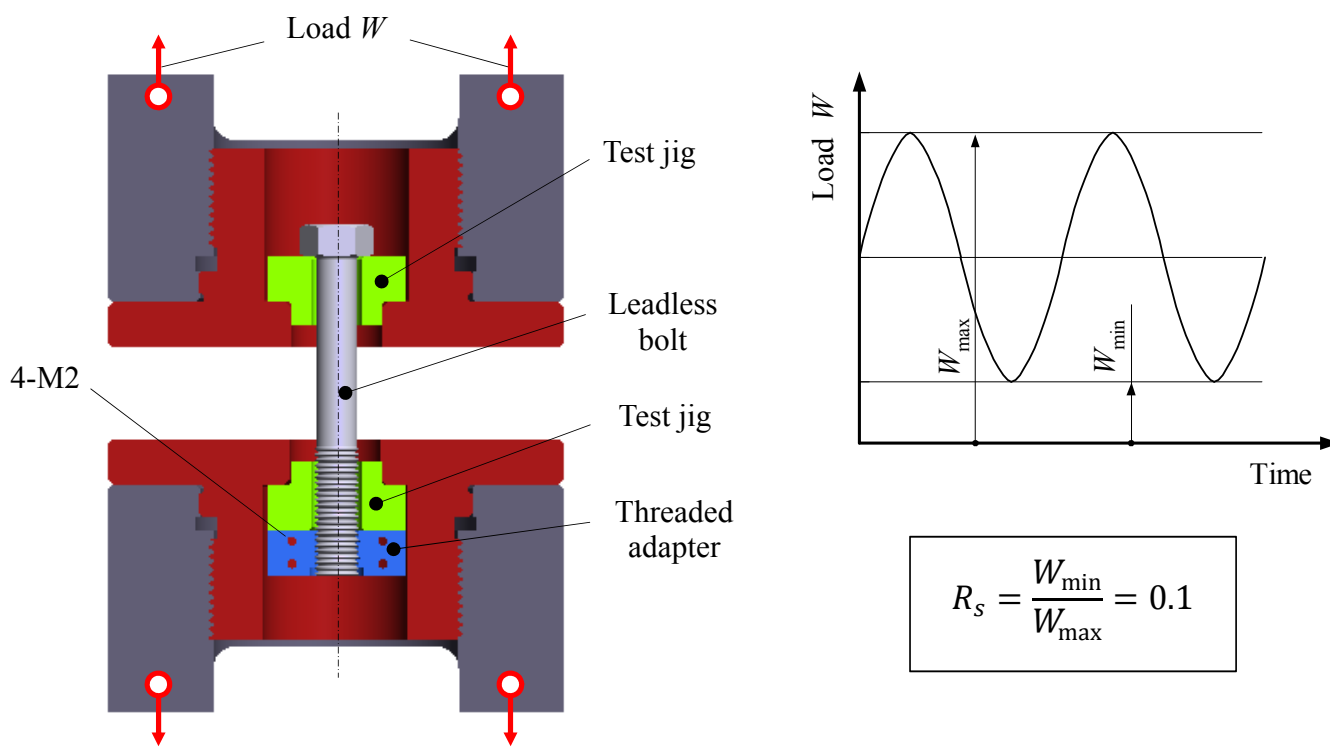

Fig.12 Setup and the loading condition of the fatigue test

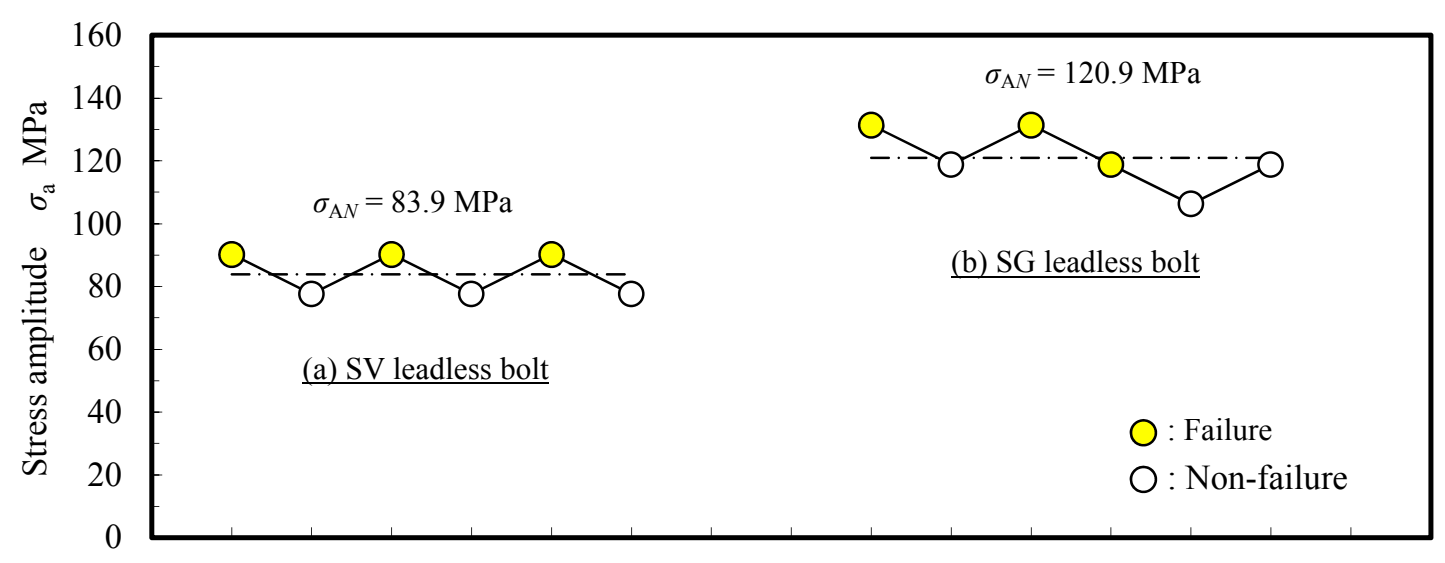

Fig.13 Results from staircase fatigue tests 


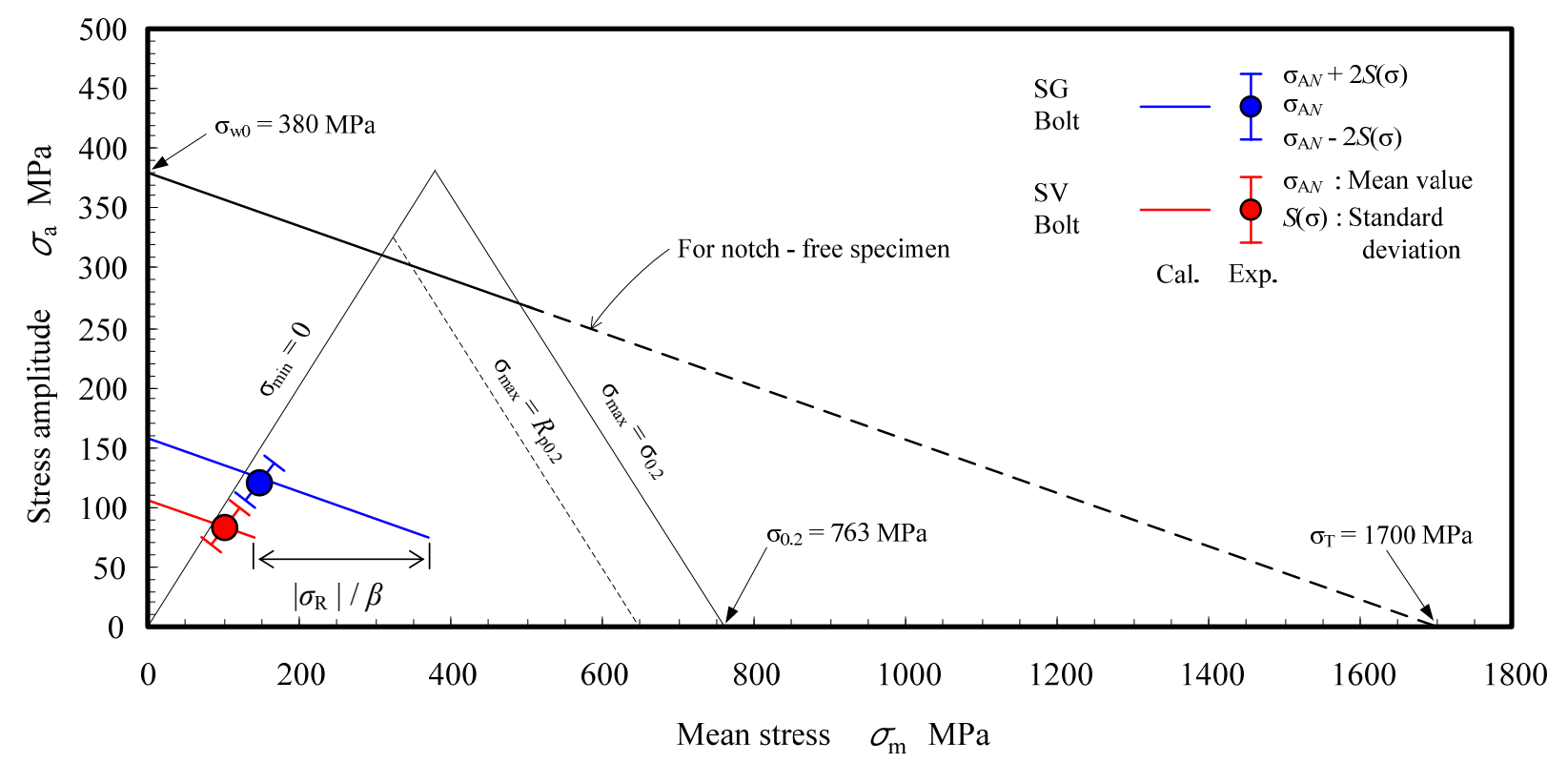

Fig.14 Fatigue limit diagram drawn by nominal stress

The fatigue strength of SG bolt (blue line) drawn by using Yoshimoto's hypothesis with the axial residual stress of $830 \mathrm{MPa}$ obtained by the FE simulation at the depth of $\varepsilon_{0}=30 \mu \mathrm{m}$ layer and the estimated fatigue notch factor $\beta=3.6$ shows good agreement with the experimental result (plot marked $\bigcirc$ ). This means that the axial residual stress generated in thread rolling process estimated by the simulation performed in clause $\mathbf{4 . 2}$ may also be reasonable in terms of the effect on the fatigue strength. At this moment, Yoshimoto's hypothesis cannot perfectly be verified since the depth $\varepsilon_{0}$ is still unknown. Furthermore, to enable the estimation of the fatigue strength of actual bolt/nut assemblies from the material properties and the manufacturing conditions, it is necessary in the future study to clarify the effect of thread lead on the local stress conditions on the thread root. However, the method proposed and the results obtained in this study offer a great step to achieve this purpose.

\section{Conclusions}

The main conclusions obtained in this study are summarized as follows:

(1) A method was proposed to simulate the axial residual stress distribution induced in thread rolling process by using 3D FEM which simulates not all through the process but just before final process with precisely determined material properties.

(2) The method was applied to the rolling process of the grooved specimen and the leadless bolt specimen.

(3) The axial residual stress distribution obtained for the grooved specimen showed very good agreement to one measured by X-ray diffraction method, and the validity of the method proposed was confirmed.

(4) The radial distribution of the axial residual stress on a SG bolt thread root by thread rolling which had been left unknown for more than thirty years was obtained, and the compressive residual stress at the $30 \mu \mathrm{m}$ inner layer from the thread root which may influence directly on the fatigue strength was estimated as $830 \mathrm{MPa}$ by the simulation proposed.

(5) The fatigue strength of SG leadless bolts were evaluated using SV bolts without residual stress as a reference, and it is confirmed that the effect of the residual stress upon fatigue strength can be explained by using Yoshimoto's hypothesis with the axial residual stress estimated for SG bolts.

\section{Acknowledgement}

The authors would like to give their sincere thanks to Mr. Kazunari Kamiya (graduate student of Nagoya institute of technology) who provided helpful data for fatigue strengths of the leadless bolts. 


\section{References}

Furukawa, A. and, Hagiwara, M., Relationship between Fatigue Strength of a Bolt and the Residual Stress at the Thread Root -1st report : Residual Stress on the Groove-Rolled Specimen-, Transactions of the Japan Society of Mechanical Engineers. Series C, Vol. 75 No. 752 (2009), pp. 1094-1099 (in Japanese).

Furukawa, A., Kamiya, K., and Hagiwara, M., Effect of the Residual Stress on the Fatigue Strength of Bolt in Bolt/Nut Assemblies (Verification of the hypotheses using an axi-symmetric bolt model), Journal of Advanced Mechanical Design, Systems, and Manufacturing, Vol. 6 No. 1 (2012), pp. 189-197.

Hagiwara, M., Nakahara, K., and Yoshimoto, I., X-ray Measurement of Residual Stress on Bolt Threads, Transactions of the Japan Society of Mechanical Engineers. Series C, Vol. 55 No. 518 (1989), pp. 2605-2610 (in Japanese).

Hagiwara, M., Ohashi, N., and Yoshimoto, I., On the Fatigue Strength of a Bolt Manufactured by the Thread Rolling -Effect of Residual Stress at the Thread Root-, Proceeding of the 9th International Conference on Experimental Mechanics, No.3 (1990), pp. 1255-1261.

Ishibashi, T., Fatigue of Metals and Prevention of Fracture, Yokendo Tokyo, (1969) (in Japanese).

ISO3800, Treaded fasteners - Axial load fatigue testing - Test methods and evaluation of results, (1993).

Kim, W., Kawai, K., Koyama, H., and Miyazaki, D., Fatigue strength and residual stress of groove-rolled products, Journal of Materials Processing Technology, No.194 (2007), pp. 46-51.

Mitsubayashi, M., Miyata, T., and Aihara, H., Prediction of Improvement in Fatigue Strength by Shot Peening and Selection of Most Effective Peening Condition, Transactions of the Japan Society of Mechanical Engineers. Series A, Vvol. 61 No. 586 (1995), pp. 1172-1178 (in Japanese).

Nishihara, T., and Sakurai, T., Fatigue Strength of Steel for Repeated Tension and Compression, Transactions of the Japan society of Mechanical engineers, Vvol.5, No.18(1939), pp. 93-97 (in Japanese).

Okubayashi, T., Hagiwara, M., Hamada, M. and Hirooka, Y., Effect of Free-Threaded Portion of a Bolt on its Tensile Properties, Transactions of the Japan Ssociety of Mechanical Eengineers. Series C, Vvol.72, No.718 (2006), pp. 1982-1986 (in Japanese).

The Japan Society of Mechanical Engineers ed., JSME Handbook: Design materials for fatigue strength of metallic material (1982), pp. 68-73, The Japan Society of Mechanical Engineers (in Japanese).

Yoshimoto, I., A Hypothesis concerning Fatigue Strength of Bolt-nut Joints, Bull. PME (T.I.T.), No.51 (1983), pp. 43-46. [Yoshimoto, I., A Hypothesis concerning Fatigue Strength of a Bolt-nut Joints, Journal of JSPE, Vvol.49, No.6 (1983), pp. 801-803 (in Japanese)] 